\title{
Smallholder adaptation to climate change: dynamics and limits in Northern Ghana
}

\author{
Wolfram Laube • Benjamin Schraven • Martha Awo
}

Received: 5 February 2009 / Accepted: 27 July 2011 /Published online: 2 September 2011

(C) Springer Science+Business Media B.V. 2011

\begin{abstract}
Climate change and land degradation result in decreasing yields and crop failures in Northern Ghana and have caused further impoverishment of Ghana's poorest region. Farmers have diversified their livelihoods to adapt to uncertain environmental conditions in various ways. While traditionally a diversification of the production and migration were the prime means of adaptation, many farmers have started to intensify their production by adopting shallow groundwater irrigation for vegetable gardening for Ghana's urban markets. This has helped to cope with a changing environment, ameliorated poverty and reversed rural-urban migration, while the local hydrology curbed an over-exploitation of groundwater resources, commonly associated with an uncontrolled farmer-driven expansion of groundwater irrigation. This research confirms that farmer-driven small-scale irrigation can play an important role in the process of climate change adaptation. However, while farmers tried to integrate in the larger economy, they have become subject to market failures that in their essence are caused by unfair and unpredictable patterns of global trade. It is this double exposure to global environmental change and economic globalization that need to be taken into consideration when local adaptive capacities are discussed. Many convincing arguments call for the revision of some of the most unfair and devastating economic practices; however, the need to enhance adaptive capacity towards global climate change for poor parts of the population in the south should be added to the discussion.
\end{abstract}

\section{Introduction}

Environmental change and economic globalisation exert an increasingly high degree of pressure on the agricultural livelihoods of small-scale farmers in West Africa. Factors such as land

\footnotetext{
W. Laube $(\bowtie)$

Center for Development Research, Department of Political and Cultural Change, University of Bonn, Walter-Flex-Str. 3, 53113 Bonn, Germany

e-mail: wlaube@uni-bonn.de

B. Schraven

German Development Institute, Department Environmental Policy and Management of Natural

Resources, 53113 Bonn, Germany

e-mail: benjamin.schraven@die-gdi.de

M. Awo

University of Ghana, Institute of Statistical, Social and Economic Research,

P.O. BOX LG 74, Legon, Ghana

e-mail: marthawo@yahoo.com
} 
degradation and global climate change lead to declining yields and the increasing unreliability of local agricultural production systems in an area where the economies of most countries still largely depend on crop growing (Boko et al. 2007: 452ff, Collier et al. 2008: 338). At the same time, economic globalisation (in this context, an increase in international trade and the falling of political barriers) limits small-scale farmers' adaptive capacity towards climate change in the region. Local agricultural intensification and the production of cash crops for national and regional markets - patterns of adaptation commonly found throughout the region - face stiff competition from often highly subsidised agricultural products from Europe, Asia and America. As has been shown, this kind of 'double exposure' affects small-scale farmers and agricultural wage labourers in countries such as Mexico and India (Eakin 2005; O'Brien et al. 2004; O'Brien and Leichenko 2000). In order to show how this affects the their West African counterparts, this paper discusses the example of farmer-driven expansion of shallow groundwater irrigation (SGI) for the production of tomatoes in the Anayere and Atankwidi River catchments in the Upper East Region of Northern Ghana. The conclusions derived from this local study are used to discuss how far the expansion of SGI can serve as a more widespread adaptive strategy towards environmental change in semi-arid parts of West Africa.

The Upper East Region (UER) of Northern Ghana has been, since colonial times (19041957), the poorest part of the country. The area suffers from difficult climatic conditions, relatively high population density and patterns of underdevelopment, which are the result of discriminatory colonial and post-colonial policies. The population-consisting of a number of relatively small ethnic groups - is largely dependent on agriculture, a practice in which $70 \%$ of the population is engaged for their livelihoods (GSS 2002b). The UER remains the poorest region of Ghana, and levels of poverty have increased throughout the 1990s, despite considerable economic growth and an overall reduction of poverty in the country. Officially, $88 \%$ of the rural population falls below the official poverty line (GSS 2000: 13).

Climatic changes have always had, and continue to have, a large impact on local agricultural production: from the 1960s to the 1990s West Africa encountered a particularly dry period, with terrible droughts in the Sahel and the semi-arid Guinea-Savannah, particularly in the late 1970s and early 1980s, although rainfall averages have since recovered (Hulme 2001). Regional climate models predict the continuation of a moderate increase in precipitation throughout the region, but with considerable local variation (Jung and Kunstmann 2007; Paeth 2004). Furthermore, statistical analyses of rainfall patterns in the last 60 years have shown that the onset of the rainy season has shifted from April to May and dry spells during the rainy season have increased (Laux et al. 2008). According to regional climate model projections developed from the results of global climate change models, this trend will become more pronounced, and climatic patterns more unpredictable and erratic, than they were previously. This increases the probability of the occurrence of extreme events such as floods and droughts, and thus the danger of more harvest and food insecurity (van de Giesen et al. 2010).

Apart from climatic changes, large population growth has occurred over the last century, which has led to increasing pressure on natural resources such as soils, pastures and forests. Degrading resources have led to decreases in the output of the traditional agro-pastoral production system consisting of rain-fed agriculture and livestock husbandry.

As in other parts of Africa (Ellis 1998; Olivier de Sardan 1988), local peasants living in an unpredictable environment often diversify their livelihood activities as an adaptive strategy to mitigate risks and to cope with disasters. Diversification techniques within agriculture - planting different crops, differently located farm types, intercropping and animal husbandry, hunting and gathering, trade, migratory wage labour and a wide array of social institutions that enhance redistribution, reciprocity and solidarity in times of needhave helped local farmsteads to adapt to a difficult environment (Laube 2007: $151 \mathrm{ff}$, Tonah 
1993: 139 ff). Faced with increasing pressure on their agricultural livelihoods, local farmers have adopted further coping and adaptation strategies. Permanent and seasonal migrations are very important coping strategies, as they help to reduce pressure on available resources and create additional income for consumption or investment. In order to adapt to environmental changes, in many parts of the UER agricultural production is intensified, mainly through the adoption of irrigation practices and the adoption of new crop varieties (Tonah 1993: 140). The expansion of irrigated agriculture comes partly as the result of governmental efforts to enhance local agricultural production, but is nowadays very often a farmer-driven development. Initial efforts, by colonial and independent governments, to introduce medium- and small-scale irrigation, due the top-down and sometimes exploitative nature of development efforts, often encountered local skepticism and avoidance strategies (Konings 1986; Laube 2007). However, since the mid 1990s, land in government projects has been in high demand, and the farmer-driven expansion of irrigated agriculture has experienced a boom. Thousands of farmers have started the production of vegetables such as tomatoes, onions and peppers using water from perennial rivers and shallow groundwater aquifers. This development has not been instigated by the government or other development agencies; it is the result of the local adoption and dissemination of new crops, techniques and knowledge that has proved to be potentially profitable. Smallholders try to profit from new market chances, as they attempt to adapt to mounting economic and environmental pressure.

In discussions about the transformation of traditional African small-scale agriculture, peasants' will to be integrated into national and/or global economies has been frequently questioned. Traditional norms (Rostow 1987) or a local 'economy of affection' (Hyden 1980) are either blamed or praised for allowing peasants to escape (forceful) agricultural modernisation and pressure for market integration. Besides these arguments, other authors (Bates 1981; Sandbrooke 1985) point out that African peasants' withdrawal from governmentdriven agricultural modernisation and market integration results from the forceful and exploitative nature of these interventions. They argue that farmers would very likely engage in the production of cash crops, if it were profitable to do so. Indeed, like elsewhere in Africa (Tosh 1980; Austin 2008), small-scale farmers in West Africa are apt to respond to market opportunities, if conditions allow. Examples from Ghana include the cocoa and palm oil booms of the 18th and 19th centuries (Berry 1993: $68 \mathrm{ff}$ ), as well as the farmer-driven expansion of pineapple production in Ghana's South in the last decade (Conley and Udry 2001).

Interestingly, the innovative capacity shown by local farmers in the UER is not hindered but rather largely enabled by traditional norms that facilitate the sharing of resources such as agricultural knowledge, labour and land.

Vegetables grown by small-scale farmers in the UER are produced mainly for the national market, and mostly sold to traders who sell them in the urban centres of southern Ghana. Where practiced, irrigated agriculture proves to be able to enhance household incomes considerably and to decrease rural-urban migration, and farmers see it as an important means for the adaptation to (global) environmental change (Laube et al. 2008).

However, despite these benefits, irrigated vegetable production remains a risky business. Apart from crop diseases and occasional water shortages, the failure of vegetable markets limits the benefits obtainable from irrigated agriculture. Market failure is most pronounced with regard to tomato production, especially due to the perishable nature of this produce, but it also affects the sale of other vegetables such as peppers and onions. The marketing of irrigated vegetables therefore suffers from a number of flaws. In Ghana, national vegetable market channels are monopolised by highly organised women trader organisations that exert a large degree of control over commodity prices, which they frequently manipulate to the farmers' disadvantage. Furthermore, local farmers face a high degree of regional competition from other countries 
within the sub-region (Burkina Faso for tomatoes, Mali and Niger for onions). Nevertheless, the largest source of competition stems from European, American and Asian countries, where the production of vegetables is highly intensified and often also subsidised, and from where large quantities of cheap vegetables and vegetable products (such as tomato paste) are imported into Ghana. Artificially low world market prices negatively affect local prices, marketing chances and the potential for the establishment of a domestic processing industry. Patterns of regional and global economic exchange, therefore, largely limit local, small-scale farmers' adaptive capacities with regard to environmental change. This can clearly be seen in the study of patterns of local adaptation to environmental change in the Anayere and Atankwidi catchments of the UER in Northern Ghana.

\section{Research area and research methodologies}

SGI expansion is highly pronounced in the Anayere and Atankwidi catchments Fig. 1. These small river basins (approx. $200 \mathrm{~km}^{2}$ each) are inhabited by a mainly rural population, the majority of which belong to the Kassena and Nankana ethnic groups. The catchments are situated in the Kassena Nankana, Bongo and Bolgatanga Districts of the UER in Northern Ghana, but also extend in the north across the border into southern Burkina Faso. The GLOWA Volta Project (GVP) started an intensive study of SGI development in these small catchments in 2006.

As part of the GVP SGI study, anthropological field research, quantitative socio-economic surveys, farm observations and a hydrological monitoring of surface and groundwater resources were undertaken. The GVP research was complemented by the Shallow Groundwater Irrigation Project (CP 65) of the Challenge Programme for Water and Food, which enabled a continuation of socio-economic research and an intensification of hydrological studies. While assessments of hydrological aspects and the impacts of SGI are still ongoing, this paper draws on the survey results as well as the anthropological fieldwork.

Initial anthropological research began in 2005. Since then, in-depth interviews and group interviews with local farmers, farmer leaders, traders, local (neo-) traditional authorities (chiefs and earth priests) and representatives of the district and regional branches of the Ministry of Food and Agriculture have been undertaken. Intimate knowledge about the history, institutional framework and the problems and practices of SGI served as the qualitative background for a survey conducted at the end of the dry season in 2006. During this survey, 213 SGI farmers were interviewed. Since a comprehensive database of irrigation farmers did not exist, the farmers were selected purposefully. The aim was to find farmers representing different farming areas, clans, age groups and genders within particular farming areas, as well as the different types of irrigation methods (bucket and pump irrigation) used.

The questionnaire addressed various issues such as the demographic background of the respondents, the composition and asset endowment of households, migratory patterns, dry and rainy season production, access to land, water, agricultural inputs and capital, the benefits and problems of SGI, as well patterns of produce marketing. In 2008, a panel survey of largely the same sample was conducted in order to analyse changes and similarities over time.

Another survey was conducted in 2007, the major purpose of which was to compare the socioeconomic characteristics of irrigation and non-irrigation households. This survey included 150 households comprising a total aggregated sample population of 1,003 people. ${ }^{1}$ This sample size,

\footnotetext{
${ }^{1}$ To guarantee a valid simple random sample, all households of the Atankwidi catchment were identified in a satellite image and listed accordingly. Based on the list, a random sample was drawn. The sample was generously provided by Dr. Julia Schindler (for further details, see Schindler (2009:58-59)).
} 


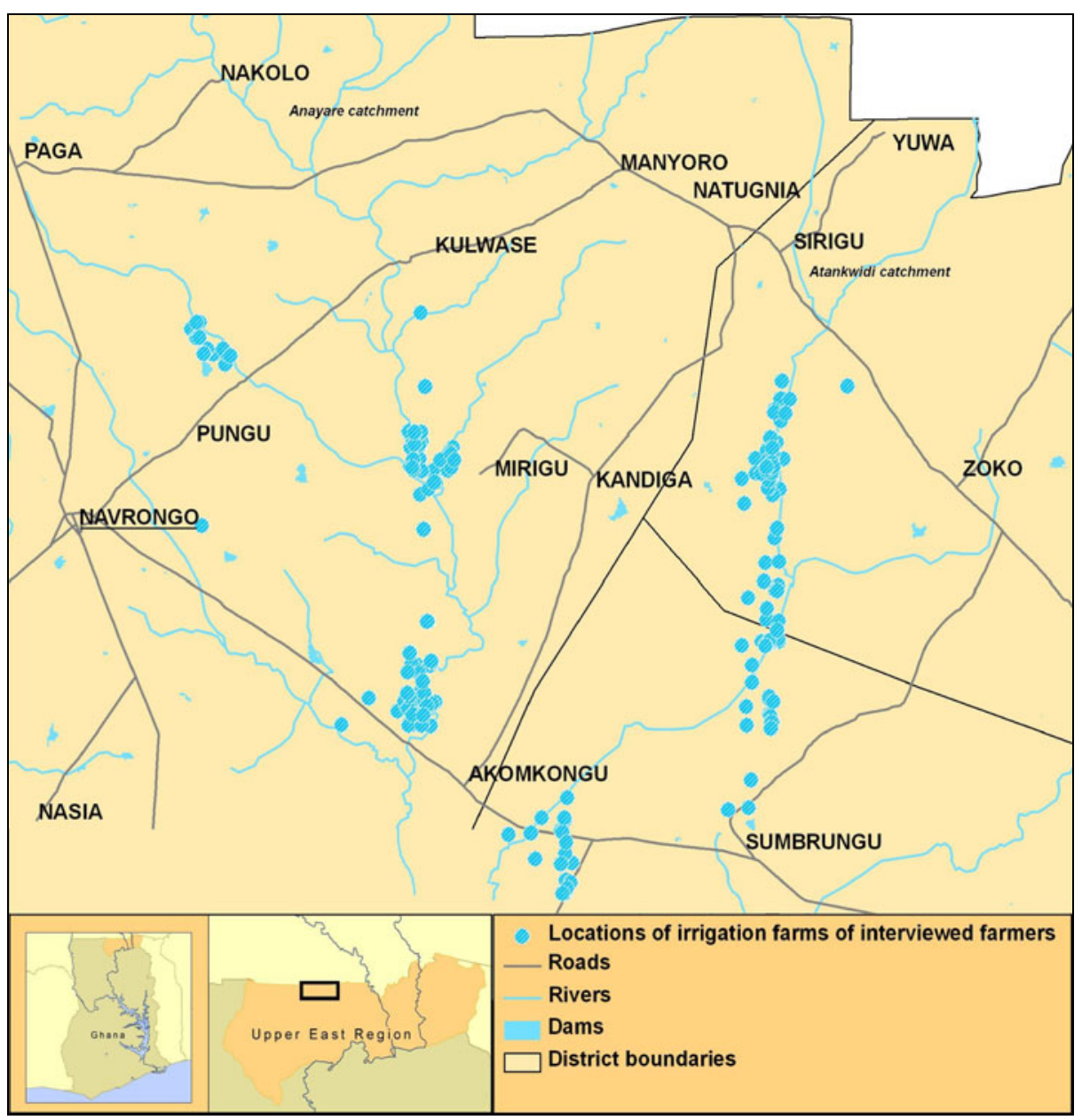

Fig. 1 Map of the Anayere and Antakwidi catchments (Source: own presentation)

according to Levy and Lemeshow's (1999:74) equation for the determination of simple random sample sizes, guarantees a maximal relative difference of $8.3 \%$ of the true population value given a confidence level of $95 \%$ and an estimated share of households that are into SGI of about $35 \%$ (as stated in older studies). The underlying population figure for the Ghanaian part of the Atankwidi catchment was estimated at 38,095 , whereas an estimated proportion of $13.5 \%$ of the population - also based on older studies - with access to 'official' dam irrigation farming was already subtracted, since dam irrigation households were not perceived as part of the relevant population. The most recent population data for the Atankwidi catchment is from census data from the year 2000 collected by the Ghana Statistical Services. At that time, the total number of people living in the accordant survey area was stated at 41,091 (including farm households with access to dam irrigation). Besides the subtraction of population shares with dam irrigation access, this official population number was multiplied by a population growth rate for the time period between 2000 and 2007, which was estimated at 7.2\% (based on the five-year growth rate of $5.1 \%$ for the Kassena-Nankana District, one of the riparian districts of the catchment (GSS 2002a, b; information provided by the Kassena-Nankana District Assembly)). 
The surveys were conducted with the help of local enumerators, who were trained specifically for the purpose. The interviews were conducted in English, Twi and the local languages Kasem and Nankam. MA and $\mathrm{PhD}$ research provides further qualitative and quantitative information about migratory patterns and crop marketing (Awo 2007; Amegashitsi 2009). Secondary data provides further background for the paper.

\section{Climate change and environmental degradation}

The study area belongs to the West-African semi-arid Guinea Savannah belt (Adu 1972). The standard 'climatic year' can be divided into two seasons: the dry season from November to April/May, with only marginal rainfall, and the wet season from June to October. The amounts of rainfall in Northern Ghana vary quite substantially according to the location. In most parts of the Upper East Region, for instance, levels vary from 1,000 up to 1,300 $\mathrm{mm}$ per annumin some parts even less. Most of the precipitation (about 60\%) normally can be expected from July until September when the mean annual temperature averages $28.6^{\circ} \mathrm{C}$. In March and April, usually the hottest months at the end of the dry season (Kranjac-Brisavljevic et al. 1999: $5 \mathrm{ff}$.), the average temperature is more than $32^{\circ} \mathrm{C}$.

In qualitative interviews, farmers mentioned that within the last 20 years the number of years experiencing a belated onset of the rainy season (May or June instead of April) has increased. Traditional signs for the onset of the rainy season (certain behaviours of birds and ants, changing wind patterns, the coming of new leaves, etc.) have become unreliable (see Dietz et al. 2004: 159 for similar findings on Northern Ghana, or Roncoli et al. 2002 for similar findings in neighbouring Burkina Faso). Climate models for the region project that the shift in the onset of the rainy season will continue further in the coming decades. According to these projections, between 2030 and 2039 the rainy season might only start in June or even later in Northern Ghana (Jung and Kunstmann 2007). For Northern Ghana and Southern Burkina Faso (Laux et al. 2008: 130), it is estimated that the average onset of the rainy season ${ }^{2}$ may shift from the 140th day (estimated average for 1961-2000) to up to the 171st day (estimated average for 2001-2040) of the Julian calendar. He also predicts (ibid. 181) that the standard deviation for the onset of the rainy season will increase, which means that not only will it shift but also it will become even more 'erratic'.

From a long-term perspective, rainfall levels in wide parts of West Africa have changed. From 1970 up to the beginning of the 21 st century, the decrease rate of mean annual rainfall levels ranged from about $10 \%$ for the wet tropical zone to more than $30 \%$ for the Sahelian zone (Niasse 2005: 4). For the whole Volta Basin, the mean precipitation amount decreased by $10 \%$ from $1,100 \mathrm{~mm}$ per year between 1901 and 1969 to $987 \mathrm{~mm}$ per year between 1970 and 2002 (Kranjac-Brisavljevic et al. 1999: 5 ff.). In particular, the period between the late 1970 s and the late 1980s was a decade with very severe droughts that especially affected West Africa and the whole of the Sahel region. On the other hand, a clear increase in rainfall amounts since the late 1980s and early 1990s can be observed (Hulme 2001), which is why some authors interpret the rainfall trends during the 1970 s and 1980s as major climate deterioration rather than as indicators of a process of long-range climate change

\footnotetext{
${ }^{2}$ Laux et al. (2008: 331-332) took a definition of the onset of the rainy season that depends on rainfall alone and at the same time reflects typical crop water needs in the region. The onset of the rainy season was defined by: (1) A total of at least $25 \mathrm{~mm}$ of rainfall in a five-day period; (2) At least three wet days (at least $0.1 \mathrm{~mm}$ of rainfall) in that period; and (3) no dry period longer than a week in the following 30 days. Given that these constraints of the definition did not yield an onset date for every year, a fuzzy logic approach was used to facilitate modelling.
} 
(Dietz et al. 2004:154-157). Climate models do not predict any significant changes in rainfall amounts for the few next decades (despite an assumed shortening of future rainy seasons). Since the predicted ends of the rainy season are set to remain quite stable in the months of October and November, rainfall intensity during the wet season will increase and the wet season planting season will become shorter in future decades (van de Giesen et al. 2010: 1034).

The shift of the rainy season, its increasing variability and the growing intensity of rainfall will magnify the probability of extreme events, as in the rainy season $2007 / 08$, when a dry spell in May badly affected the yield of early crops such as millet and pulses, while heavy rains and floods in August and September destroyed late crops such as guinea corn, rice and groundnuts, as well as a large number of local homesteads. Both events combined amounted to almost complete crop failure and necessitated the distribution of food aid in large parts of Northern Ghana, including the research area.

Besides changing rainfall characteristics, a significant increase in mean temperatures in the region between 1961 and 1990, compared to of the 30 years between 1931 and 1960 , has been observed (Kranjac-Brisavljevic et al. 1999: 7 ff.). Climate models for the Volta Basin predict that average temperatures in the Upper East Region for the decade straddling 2030-2039 will increase further by up to $1.5 \mathrm{C}$ on average as compared to the decade of 1991-2000.

However, climatic change is not the only factor driving environmental changes in the research area, which also experiences locally generated environmental change. A major factor in this context is certainly the increase in population that the region has experienced since the advent of colonial rule (Songsore 1996:55; see also Table 1).

Although population growth in the UER has not kept pace with overall development in Ghana, the local population has certainly experienced significant expansion, almost doubling in the last 40 years and increasing by approximately $70 \%$ in the Kassena Nankana District. With a density of 91-104 persons $/ \mathrm{km}^{2}$, the population is well above the average national level of 79 persons $/ \mathrm{km}^{2}$. The ratio seems high for an area with a fragile and disintegrating ecosystem.

As a result of the expansion of agricultural land, bushfires and the high demand for firewood, forest cover of the research area is vanishing. In the search for firewood, pasture and arable land, former bush areas are increasingly deforested and turned into bush farms (Blench 2006). In the period between 1990 and 2000 alone, the forest area in the Kassena Nanakana District was reported to have decreased by a rate of almost $50 \%$, whereas the forest areas in the whole Ghanaian White Volta Basin have been even reduced by a rate of more than $70 \%$ in the same time period (Table 2). Deforestation, overgrazing and bushfires have degrading effects on the already poor soils of the area, especially in bush farms, where soil fertility is not replenished through manuring (Kpongor 2007:37 ff.; Braimoh and Vlek 2005:362 ff.).

However, the intention is not to take a neo-Malthusian position by saying that population growth will inevitably entail ecological degradation, nor is the aim to blame the local population for the overexploitation of its natural environment. Neither local population growth nor increasing population densities alone contribute to degradation processes in northeast Ghana's physical environment. The negative effects of population growth could be mitigated if rain-fed agriculture was intensified and alternative economic options developed, but such developments depend largely on international developments (Songsore 1996). As part of the conditions for continued donor support, agricultural subsidies and government provision of fertilisers have been abolished since the structural adjustment programmes of the 1980s. A coupon system for the distribution of subsidised fertiliser, which was introduced before the elections in 2008, does not seem to function efficiently, 
Table 1 Population change and distribution in Ghana, Upper East Region and the Kassena Nankana District from 1960-2000

\begin{tabular}{lrrrr}
\hline & & Ghana & Upper East Region & Kassena Nankana District \\
\hline Population & 1960 & $6,728,815$ & 468,638 & 93,397 \\
& 1970 & $8,559,313$ & 542,858 & 99,006 \\
& 1984 & $12,296,081$ & 772,774 & 149,680 \\
& 2000 & $18,912,079$ & 920,089 & 149,491 \\
Increase (\%) & $1960-70$ & 27.2 & 15.8 & 6.0 \\
& $1972-84$ & 43.7 & 42.3 & 51.0 \\
& $1984-00$ & 53.8 & 19.1 & -0.1 \\
Growth (\%) & $1960-70$ & 2.4 & 1.5 & 5.1 \\
& $1972-84$ & 2.6 & 2.6 & 2.5 \\
& $1984-00$ & 2.7 & 1.1 & -0.01 \\
Population density (person $/ \mathrm{km}^{2}$ ) & 1960 & 28.2 & 53.0 & 37.2 \\
& 1970 & 35.9 & 61.4 & 60.3 \\
& 1984 & 51.5 & 87.4 & 91.2 \\
& 2000 & 79.3 & 104.1 & 91.0 \\
\hline
\end{tabular}

Source: (GSS 1989, 2002a); Note that most parts of the Anayere and Atankwidi catchments are part of the Kassena Nankana District. Population figures for the catchments are not available.

and none of the farmers interviewed during a revisit of the research area in April 2010 had actually profited from the scheme. Since 2010 subsidised fertilizer can be obtained for roughly $50 \%$ of the price from private vendors, but it is too early to draw any conclusions on the functioning of the system. As a result, the intensification of rain-fed agriculture, which is one possible adaptation strategy in the case of population growth (Boserup 1965), is not really an option in the research area, especially since increasing climatic variability renders high investments in rain-fed agriculture extremely risky. Social specialisation, economic diversification and technological innovation are all factors which have mitigated population pressure on natural resources elsewhere in Africa (Tiffen et al. 1994), but in the research area population growth rather led to an expansion and permanent use of farmland (Songsore 1996).

However, the agricultural practices of local farmers in Africa have proved to be more adaptable to their environment than either scientists or administrators often believe (Fairhead and Leach 1996). In the following chapter, (traditional) patterns of local environmental adaptation and risk management—besides SGI—will be discussed.

Table 2 Decrease of land area covered by forests in selected districts of the Ghanaian White Volta Basin from 1990-2000

Land area covered Land area covered Change in $\%$ by forests in 1990 in $\mathrm{km}^{2}$ by forests in 2000 in $\mathrm{km}^{2}$ in $\mathrm{km}^{2}$

\begin{tabular}{lrrrr}
\hline Bongo District & 32 & 30 & 2 & 6.3 \\
Bolgatanga District & 688 & 181 & 507 & 73.7 \\
Kassena Nankana District & 294 & 152 & 142 & 48.3 \\
Ghanaian White Volta Basin & 4891 & 1408 & 3483 & 71.2 \\
\hline
\end{tabular}

Codjoe 2004: 181 


\section{Local risk management, coping strategies and environmental adaptation}

Peasants living in difficult environments have developed ways to adapt to the particular circumstances of unpredictable environments for centuries. They rely on risk-mitigating patterns of production (Carter 1997), the diversification of agricultural production (subsistence and market production) (Elwert 1983; Ellis 1998), alternative sources of livelihood (Bryceson 2002) and different coping strategies in the case of disaster (Scott 1976; Olivier de Sardan 1988; Adams et al. 1998). In order to reduce risk in agricultural production, peasants in the research area plant and intercrop different crop types across different growth periods and with diverse moisture requirements, and cultivate farms in different locations (compound farm, family farm, bush farm) with different soil types to increase the chance that at least some crops will survive under extreme weather conditions (Laube 2007: 151 ff; Tonah 1993: 139 ff). Additionally, peasant households in the study region engage in livestock husbandry. The raising of cattle, goats, sheep, donkeys, pigs and different varieties of fowl is increasingly integrated into crop growing, as it provides manure and animal traction (Whitehead 2006). It also serves important nutritional needs and is seen as a coping strategy in case of food shortages that may occur as the result of droughts or floods, although in many poor households they regularly occur in the rainy season before harvest, and so the animals are sold to purchase food items during these times (Adams et al. 1998: 268; Tonah 1993: 142). Livestock also has strong socio-cultural value, as livestock ownership symbolises social status and acts as currency in many important social and ritual contexts such as marriages and funerals, as well as in traditional religion (Laube 2007).

Hunting, fishing and gathering are also part of many households' livelihood portfolio (Tripp 1992: 252). While these activities directly supplement household food requirements, prey, fish and fruits are also sold at local markets (Laube 2007). Many women gather the fruits of the Shea (Vitellaria paradoxa) and Kapok tree (Ceiba pentandra), process them partly, and then sell the produce via intermediaries in national or even global markets (Chalfin 2003). Petty trade, mostly by women, in agricultural produce, processed foodstuffs and beverages, as well as petty industrial commodities, is an additional source of income in most peasant households, while some men engage in the profitable long-distance trade of animals (Tripp 1992: 254). A wide array of social institutions, such as norms and values that enhance redistribution, reciprocity and solidarity in times of need, for instance through the sharing of land, labour and food, seed lending, reliance on in-laws and the redistribution of foodstuffs through funerals, have helped local farm households to adapt to a difficult environment (Laube 2007; Tonah 1993).

As environmental change threatens their agricultural livelihoods, local households have adopted different adaptation strategies. The reduction of planting time that comes along with the shift of the rainy season has affected traditional cultivation patterns. Types of millet or guinea corn that have a long growth period are substituted by other types that mature faster (Tonah 1993: 140). The same is true for local types of groundnuts, which are replaced by fast-growing varieties (Dietz et al. 2004:159). These patterns of change were confirmed during group discussions with farmers, who also indicated that the cultivation of groundnuts in less fertile soils, and the production of short-growing varieties of maize (with the application of chemical fertiliser), are increasing (Laube and Le 2007).

To adapt to declining soil fertility and low soil moisture, local farmers have in recent years adopted new techniques such as composting, the application of green manure from legumes and paddy rice cultivation, which are based partly on indigenous and partly on external knowledge (Derbile et al. forthcoming). 
A very important strategy for not only coping with crises and endemic poverty, but also adapting to a changing environment is labour migration to southern parts of Ghana. Initially, migration was the result of coercive labour recruitment (Lentz 1998), but subsequently many people ventured to the south voluntarily, as they wanted to earn money to be able to pay bride prices, buy goods or animals, to receive education or because they had to pay taxes (Nabila 1987). Other people travelled out of curiosity or to escape family problems. Voluntary migration gained increasing importance for the people of the North and reached huge proportions by the end of the 1920s. Meyer Fortes (1936) estimated that $15 \%$ of the adult men of the neighbouring Tallensi were working in the South in 1935 . On the basis of a conservative estimation of an annual population growth of $2.6 \%$, it is estimated that the low population growth of the Kassena Nankana District between 1948 and 1960 (from 91,051 to 93,397) is attributable to the out-migration of about 26,000 people, i.e., almost $20 \%$ of all people born in the district (Kumedzro 1970). A high outmigration rate also accounted for the fact that the population of the Kassena Nanakana District remained almost unchanged between 1984 and 2000 (see Table 1). Migrants go to southern Ghana in search of work in the mining sector, the plantation economy or in the urban areas. Some permanent migrants work continuously as labourers, while others obtain land or open businesses. Many migrants stay for a number of years in the south and later return to take over family responsibilities or to start their own families.

Seasonal migration usually takes place during the dry season, when agricultural production comes to a halt and demand for labour in the south is high. This is also the time when food stocks in northern peasant households run drastically low, especially in years with poor harvests. Farming households view the fact that there are 'fewer mouths to feed' as a major benefit of seasonal migration, which seems even more important since the value of gifts or remittances migrants may provide is decreasing (see below). Some seasonal migrants also travel after planting rainy season crops, and only return for the harvest. In this case, remaining family members will take care of the farms during their absence.

However, the local 'culture of migration' (Lambert 2002) that appreciated migration because of the opportunity to gain experience and accumulate some wealth, seems to be disappearing - along with the number of seasonal migrants. Interviews with farmers and migrants showed that people in the research areas are increasingly aware of the risks and disadvantages of migration, namely lack of social support, exploitation, behavioural changes and crime. Awareness of the danger of contracting infectious and often deadly diseases (especially HIV/AIDS) has also risen. At the same time, the profitability of seasonal migration is decreasing. Difficulty in finding jobs, provisions for employment agents and, given an abundance of labour, low wages, as well as the greatly rising cost of food, accommodation, and transport, have made migration less attractive. This is particularly the case for those small-scale farmers able to create additional income through shallow groundwater irrigation (Amegashitsi 2009; Schraven 2010). However, seasonal migration continues to be an essential source of additional income for non-irrigation households, and remains an important coping strategy in crises (see Lay et al. 2009 for similar patterns of migration in neighbouring Burkina Faso). Those in need continue to travel south after the dry season harvest, and return after 2 months to prepare rainy season farms. This pattern was clearly evident in late 2007, when after a combination of drought and floods, many households lost their crops and many young people went to the south in search of jobs. This is also reflected in our survey results - in 2007, in about $30 \%$ of irrigation households, seasonal migrants went to the south, while in 2006 and 2008 the number of irrigation households with seasonal migrants was half as low. The share of households with seasonal migrants among the non-irrigation group is about $40 \%$. 


\section{Shallow groundwater irrigation as an adaptive strategy}

According to local informants, SGI in the research area was introduced at the beginning of the 1950s (in Pungu, a village within the Anayere Basin) by a returning migrant, who had seen well irrigation in Southern Ghana. He inspired the colonial agricultural services, which started to construct lined wells for those willing to produce vegetables in the dry season. The vegetables produced were consumed locally in part, but mainly sold to the British and the missionary schools of the district capitol Navrongo. In Pungu, other farmers picked up the practice of SGI and started to construct their own wells in neighbouring parts of the village, but irrigation was not in high demand and knowledge rarely spread across village boundaries.

Irrigation became more widespread when the Ghanaian government in 1957 commissioned the construction of 104 dams in the Upper East Region, two of which lay within the Anayere catchment. The dams were fitted with irrigation infrastructure, and the Ghana Irrigation Development Authority (GIDA) tried to engage local farmers in the practice. Success was mixed, as small-scale farmers were only partly interested and GIDA's management style was authoritative. When GIDA withdrew from the management of the schemes, the programme's infrastructure collapsed and irrigation farming became impossible. However, farmers became interested and production resumed under farmer management when the dams were rehabilitated by MOFA in the late 1990s and early 2000s (Gyasi 2005: 30 ff).

The construction of two medium-scale irrigation schemes in Tono and Vea, from the late 1960s until 1985, influenced regional irrigation development. This construction was preceded by compulsory land expropriation. Uprooted from their ancestral grounds, and deprived of compensation, the construction of the irrigation schemes was a traumatic experience for a large number of local peasants. During land allocation in the irrigation schemes, state farms and commercial farmers were also favoured (Konings 1986). Later on, when state farms collapsed, most commercial farmers lost interest in farming, and as political pressure to consider the original landholders mounted, land was redistributed to small-scale farmers. However, in the early 1990 s, local smallholders were only partially interested in irrigation, and large tracts of project land lay idle. From the mid-1990s onward, demand for irrigable land has increased, and has even led to land conflicts in Tono and Vea (Laube 2007: $97 \mathrm{ff}$ ).

The governmental promotion of irrigation in small- and medium-scale irrigation schemes only benefited a minority of farmers. Therefore, faced with the decline of rainy season farming and increasing poverty, hundreds of small farmers started to develop their own irrigation facilities and established vegetable gardens along the dry riverbeds of the Anayere and Atankwidi rivers in the mid-1990s. Our survey among SGI farmers showed that in 2006 more than $80 \%$ of them had less than 10 years of irrigation experience, while more than $57 \%$ of the farmers had only practiced irrigation for 5 years.

Farmers use shallow groundwater, which they harvest from wells and dugouts. The water is extracted mainly by manual means using buckets, but a smaller group of farmers also uses motor pumps. In 2006, the mean size of farms irrigated by bucket was roughly $600 \mathrm{~m}^{2}$ ( $\left.0.06 \mathrm{ha}\right)$, while the average size of pump farms about 2,000 $\mathrm{m}^{2}(0.2 \mathrm{ha})$. According to a remote sensing study carried out under the SGI research project of the Challenge Project for Water and Food (CP 65), the area under SGI in the Atankwidi basin alone has reached more than 387 ha, representing $1.4 \%$ of the total land area (Barry et al. 2010).

The development of SGI has hinged on a number of preconditions. Tomato production in the UER comes at a time of the year when climatic conditions in the south do not allow 
for vegetable production. Therefore, medium-scale irrigation schemes have attracted traders, who buy vegetables from the area to cater for the high demand in southern Ghana (Clark 1997: 73ff). Since the early 1990s, the enhancement of road access to Northern Ghana has largely facilitated this trade. Small-scale farmers have responded to the newly developing market chances after seeing how profitable tomato production can be.

Nevertheless, the expansion of SGI also depends on local norms and values that facilitate the sharing of knowledge, land and labour. Since agricultural extension services are missing, farmers depend on the knowledge and experience of their colleagues, in order to be able to adopt irrigation techniques. From in-depth interviews with farmers and key informants, the following history of SGI expansion can be deduced.

The techniques and knowledge involved in SGI diffused from development kernels such as Pungu. Farmers from Mirigu and Doba in the lower parts of the Anayere catchment saw the benefits of SGI and also adopted and learned from the initial irrigation farmers' methods. From there, knowledge and techniques were exported to Kandiga in the Atankwidi catchment and then spread further throughout the catchment. At the same time, farmers from medium-scale irrigation schemes, who lacked access to water and land, or simply wanted to escape the control of agricultural bureaucracy in the schemes, started to develop shallow groundwater pump irrigation in the lower parts of the catchments. Making considerable profits, a number of bucket farmers also started to invest in motor pumps, in order to be able to expand their acreage.

The diffusion of irrigation techniques, and of the know-how involved in vegetable production, is clearly the result of the willingness and ability of small-scale farmers to share knowledge. Similar to the results of other research on the diffusion of agricultural innovations among Ghanaian farmers (Conley and Udry 2001), SGI has a very strong family-based social learning component: SGI adopters are usually taught by their parents, siblings, members of their extended family or friends (Fig. 2).

To start, irrigation farmers need to own or gain access to land where shallow groundwater can be tapped easily. As land used for SGI is usually along rivers or in floodplains, not all farmers own suitable land. Within our sample, $62 \%$ of bucket farmers and about $50 \%$ of pump farmers actually practiced SGI on their own land. A large number of farmers depend on land owned by others. Land in the research area is usually controlled by local spiritual leaders, the earth priests, who are perceived as the successors of the settlers who first inhabited a certain portion of land, although these claims are frequently contested, as different claims about who is a 'first-comer' and who is a latecomer exist

Fig. 2 Sources of irrigationrelated knowledge (2006)

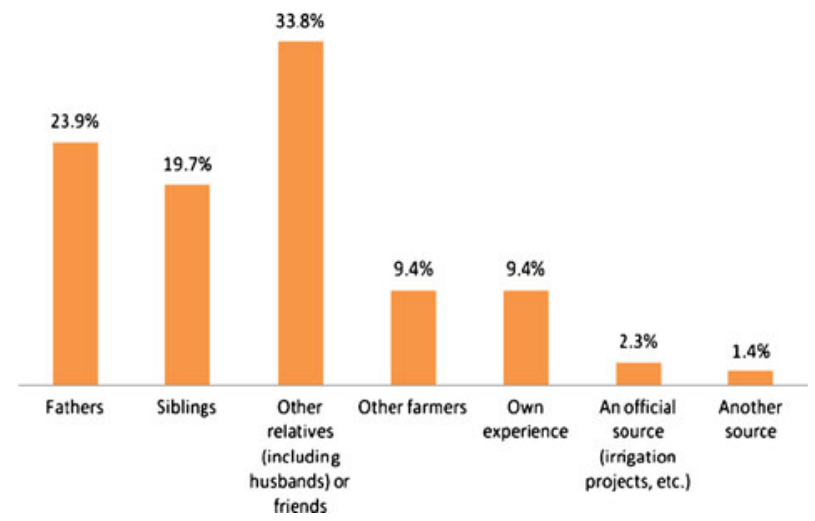


Table 3 Relationship between tenants and landlords (2006)

\begin{tabular}{lr} 
Relative by blood & $66.3 \%$ \\
In-law & $3.6 \%$ \\
Friend & $15.7 \%$ \\
Neighbour & $4.8 \%$ \\
No relationship & $8.4 \%$ \\
\hline
\end{tabular}

(Laube 2007:120 ff, Lentz 1998:53-54). Most of the land available has been distributed to local clans and is controlled by (usually male) family and household heads. This land is perceived as family property that will be bequeathed patrilineally, and cannot be reclaimed by the earth priests. Farmers without their own irrigable land must approach landowners or earth priests to gain access to land suitable for SGI (see Table 3). Land is often obtained from relatives, in-laws or friends (see Table 3), who are willing to share land during the dry season, since they usually lack the necessary labour and capital to farm all the land themselves. During the rainy season, the land reverts to the original owner. Usually land is not rented, but instead is either obtained for free or in exchange for traditional tokens such as fowl, kola nuts and local gin, as well as a certain proportion of farm produce after harvest. Only in a limited number of cases have actual cash payments been reported. However, increasingly, the gift of farm produce has started to be replaced with cash payments (the shelf life of vegetables is too short). Commercial farmers who engage in pump irrigation are now frequently asked to pay substantial amounts for land. However, local landowners are always quick to maintain that land cannot be rented, as it is traditionally inappropriate to cash in on fellow farmers trying to better their lot.

Considering that SGI is highly labour intensive and that land preparation and the digging of wells often exceed the capacities of individual farmers or even households, labour exchange is common practice. Individual farmers invite relatives and friends to come to their farms if they are in need of labour. In turn, the farm owner will provide food and drink and will have to reciprocate labour, when they are called upon. Pump farmers especially employ wage labour. The labour opportunities created through SGI are an important income source for poor households during the lean spell at the end of the dry season. SGI also helps poor bucket farmers to raise the capital for the purchase of agricultural inputs such as fertiliser and agrochemicals, and some are even able to buy pumping machines to enhance their production.

Practices such as land sharing and labour exchange have helped many poor households to engage in SGI. The impact of SGI on the economic situation and adaptive capacity of small-scale farmer households cannot be underestimated. As has been shown for India and Pakistan, farmer-driven, small-scale irrigation has the potential to reduce poverty and trigger larger development dynamics (Hussain and Ahanjra 2004).

Despite the small size and low input levels, farmers are able to reap substantial benefits from their farms. In 2006 and 2008, respectively, bucket farmers gained an average profit of about 1.5-2 million Cedis (approximately 160-200 USD) from their farms. Pump farmers earned considerably more (about 5.5 - 4.5 million Cedis (approximately $580-450$ USD). Given the fact that more than $80 \%$ of the population of the UER region has an overall income below the official poverty line of 900,000 Cedis (GSS 2000: 13), the additional income gained through SGI is substantive. Farmers therefore see SGI as profitable, and the additional income is spent mainly on household purchases such as additional food purchases, farming inputs, education, health, buildings, means of transport and the purchase of animals. A larger share of pump farmers than bucket farmers is able to make more costly investments in buildings, education and farm inputs (see Table 4). 
Table 4 Expenditure of dry-season profits per farmer type (\%)

\begin{tabular}{lcc}
\hline & Pump farmers & Bucket farmers \\
\hline Household expenditures & $92.9 \%$ & $87.1 \%$ \\
Education & $35.7 \%$ & $20.6 \%$ \\
Buildings & $45.2 \%$ & $22.9 \%$ \\
Animals & $33.3 \%$ & $30.6 \%$ \\
Farm inputs & $26.2 \%$ & $15.9 \%$ \\
Health & $9.5 \%$ & $8.8 \%$ \\
Means of transport & $4.8 \%$ & $1.8 \%$ \\
\hline
\end{tabular}

The impact of SGI can also be seen when the wealth of irrigation households and nonirrigation households is compared. ${ }^{3}$ Table 5 shows that the average wealth indicator of irrigation households is almost twice as high as that for non-irrigation households.

While it seems clear that SGI has helped small-scale farmers in the research area to adapt to an ever changing environment, it is difficult to establish a straightforward relationship between the factors of (environmental) change and particular patterns of adaptation (Nielsen and Reenberg 2009: 464, Reid et al. 2000: 340). As shown above, the research area has seen a host of social, cultural, political, demographic, infrastructural and environmental changes, which in combination have not only led to environmental degradation and persistent poverty, but also provided chances for new coping and adaptation strategies for local small-scale farmers. In an environment earmarked by population growth, regional underdevelopment, land pressure, degrading resources and changing climatic patterns, local peasants have responded to opportunities such as labour shortages in southern Ghana, infrastructure development, increasing market integration, the availability of new and advanced crop types and the spread of new types of techniques and knowledge. Adapting to (environmental) pressures, but also taking opportunities opening up, they have modified rain-fed agriculture (different crops and crop types, different agricultural calendars) and diversified their livelihoods through trading, migration and SGI. By adding historical depth to the description of the adaptation of livelihood strategies, and by referring to the explanations given by local farmers themselves, we have tried to show some of the pathways or trajectories of change (Scoones 2009: 188ff). In past decades, migration has been the major adaptation strategy with regard to population growth, environmental change and regional underdevelopment in the research area. Perceived as less profitable and even dangerous, $50 \%$ of bucket farmers and more than $60 \%$ of pump farmers reported that SGI had changed their migration patterns. In 2007 , in $31 \%$ of the irrigation households and $41 \%$ of the non-irrigation households had members seasonally migrating. The number of migrants from irrigation households was quite high in 2007, because irrigation farmers faced severe tomato marketing problems in the dry season of 2006/2007. Consequently, many farmers lost their capital for SGI. In 2008, marketing was much better and the percentage of irrigation households with seasonal migrants reduced to $16 \%$.

\footnotetext{
${ }^{3}$ To measure wealth difference, a wealth indicator was generated. The indicator is based on the quantity of household assets such as radios, pumps, bicycles or TVs, as well as on the quantity of the livestock owned. In the wealth score, assets owned by households were weighted according to their average market prices in Navrongo, as established by a market survey in 2006. The same weighting factors were used for the asset data of 2006, 2007 and 2008, since price relations between the specific items had not changed significantly.
} 
Table 5 Wealth indicators of irrigation and non-irrigation households (2007)

\begin{tabular}{|c|c|c|c|}
\hline \multirow[t]{4}{*}{ Wealth indicator } & Non-irrigation households & Mean & 24.9 \\
\hline & & Std. Deviation & 26.6 \\
\hline & Irrigation households & Mean & 46.0 \\
\hline & & Std. Deviation & 48.5 \\
\hline
\end{tabular}

The research area is not the only area in Northern Ghana where these patterns of farmerdriven SGI expansion can be observed, as they also take place in neighbouring parts of the Bolgatanga and Kassena Nankana districts, but since this development is not officially promoted accurate figures about the number of farmers and/or hectares are lacking. Focusing on a different crop, onions, small-scale farmers in the Bawku East and Bawku West districts of the Upper East Region have equally expanded SGI. Introduced in the 1930s by Mossi immigrants, and largely practiced at irrigation dams (Sinnadurai and Abu 1977: 312, Padmanabhan 2007: 65), SGI onion farming has greatly increased since the late 1990s. As in the research area, SGI expansion in Bawku seems to involve both rich and poor farmers, as well as women and youths (Whitehead 2002: 593).

In general, areas of valley bottomland that yield good quality groundwater are seen as vital resources for many African small-scale farmers that 'represent important insurance and income' for small farmers, who 'may need to increasingly depend upon them in future' (Carter and Howsam 1994: 285). Recent findings indicate that groundwater is used on 1-2 million hectares of cropped area in sub-Saharan Africa (SSA) and supports $1.5-3 \%$ of the rural population (Giordano 2006: 310). However, it is estimated that only $0.2 \%$ of the groundwater that could be used sustainably in SSA is actually tapped. Governments and international donor agencies greatly emphasise the need to expand irrigation in SSA, for instance under the Comprehensive Africa Agriculture Development Program (CAADP) or the New Partnership for Africa's Development (NEPAD) initiatives, to accelerate growth, eliminate poverty and hunger and to promote adaptation towards climate change (World Bank 2007: 13). This expansion will not only be brought about through renewed investment in medium- or large-scale irrigation infrastructure, but will also be achieved through increasing small-scale irrigation projects such as SGI. Small-scale irrigation can be locally developed and is often less costly as well as less prone to elite capture and the unequal distribution of resources and benefits than large-scale irrigation (Comprehensive Assessment of Water Management in Agriculture 2007: 176 ff). Highly attractive to local farmers and a farmer-driven alternative to costly state-driven irrigation development, SGI in Northern Ghana, nevertheless, faces a number of drawbacks that limit potential adaptive capacity.

\section{Limits of shallow groundwater irrigation as an adaptive strategy}

Despite the obvious benefits SGI provides, a number of risks are also associated with this practice. Both in group discussions and in surveys, farmers mentioned crop marketing, crop diseases and water shortages (ranked in descending order) as the main problems related to SGI. Almost $60 \%$ of the farmers interviewed stated that they had formerly lost crops due to water shortage. The situation was particularly bad in 2006, when after a series of years with rather poor rains the shallow groundwater table had become low, and so many farmers decided to engage in SGI. Some had to dig up to $8 \mathrm{~m}$ deep to find water, while others were less lucky and hit an impermeable layer without reaching water. However, after floods in 
late 2007, the shallow groundwater table increased greatly, and was still very high after the end of the farming season in 2008.

It is clear that SGI is highly dependent on rainfall patterns, and can only help to adapt locally to environmental change as long as sufficient percolation occurs and finite resources are not overexploited. Hydrological research in the Atankwidi basin, conducted under the GLOWA Volta and the SGI (CP 65) projects, points to the fact that SGI at the current level is sustainable and could be even slightly expanded (Barry et al. 2010). Patterns of shallow groundwater recharge observed during the 2007 floods also suggest that the shallow groundwater table might even improve if climate change leads to an increase of extreme events (floods). However, the sustainability of SGI is an important factor to be kept in mind. Experiences in South Asia, the Middle East or in North Africa show that the expansion of groundwater irrigation can be a way out of poverty, but conversely can lead to the overexploitation of available groundwater resources, which has serious drawbacks both for the environment and for alternative water uses/users (Comprehensive Assessment of Water Management in Agriculture 2007).

Crop disease is a factor that also affects SGI negatively. In the absence of any extension services, farmers rely heavily on trial and error when it comes to the treatment of plant diseases. They may learn from each other, and in the case of major crises even try to look for help from medium-scale irrigation schemes. Nevertheless, even here extension is poor and expertise lacking. In the dry season of 2003-04 a tomato disease hit the UER, and hundreds of hectares of tomato farms, both in formal schemes and in areas with SGI, were destroyed after farmers had invested everything in that season's crops (News in Ghana 2004). Despite this crisis, which ruined quite a number of farmers, the area farmed in the following dry season hardly decreased.

Marketing problems and regional as well as global competition threaten the profitability of SGI and its adaptive capacity the most. Tomatoes, apart from some negligible local consumption, are produced for the fresh tomato market in southern Ghana. They are sold to market ladies who arrive with trucks from the south and, with the help of local guides, loading boys and sorting girls, tour the local farming areas until they have filled their crates. In good years the relationship between farmers and market ladies is-despite some bickering about prices on both sides - relatively good. Prices vary a lot though, as at the beginning and the end of the harvesting season demand outstrips supply, while at the height of the harvesting season tomato gluts often lead to the collapse of market prices. The tomato ladies are highly organised and they are known to be able to engage in concerted action (Clark 1997). If they feel farmers' prices are too high, they stop buying tomatoes, forcing the farmers to sell their produce at lower prices, due to its perishable nature. While the overwhelming power of the tomato ladies has always aroused farmers, and has often led to bitter fighting, it should not be forgotten that, given the low quality of the trucks used and the dangers of the Ghanaian roads, the tomato trade is risky business for the traders; during harvesting time, many trucks that have been stranded or been involved in accidents can be found on the road to the south at any time.

While in the past market failure only occurred occasionally, especially during gluts, local tomato marketing has become increasingly difficult over the last couple of years. Being aware of the high demand for fresh tomatoes in southern Ghana, Burkinabè vegetable producers who lost their market in the Ivory Coast during the civil war started to attract Ghanaian traders, who started to import tomatoes into Ghana. Imports into Ghana increased from under 1,800 tonnes in 2004 to up to almost 8,000 tonnes in 2006 (Awo 2007: 27). Tomato ladies increasingly bypassed the tomato producing areas in Northern Ghana, which are just along the main road to Burkina Faso. A number of reasons have been given for this 
development. While the market ladies claim that lower prices and better quality make tomatoes from Burkina Faso more attractive, farmers and officials in the UER maintain that it is side businesses such as the sale of fruits, timber and drink - as well as the smuggling of petrol, cloth, gold or even drugs - that drive the traders to Burkina Faso.

During field research in 2007, the situation escalated. The traders completely ignored tomatoes in the UER and drove almost all their trucks to Burkina Faso, leaving the tomatoes of the Ghanaian farmers rotting. This led to bitter protests, roadblocks and the waylaying of tomato trucks on their return from Burkina Faso. As the Economic Community Of West African States (ECOWAS) regulations grant the free exchange of goods, the Ghanaian government blamed farmers in Burkina Faso for using harmful substances in the production of tomatoes, and blocked the border for 2 weeks. In the meantime, the government urged the tomato ladies to also buy tomatoes from Ghanaian farmers, which they did reluctantly. However, most of the Ghanaian farmers had already experienced great losses. Their losses were particularly large as the government promised farmers before the beginning of the growing season that an old tomato factory at Pwalugu, which had collapsed in the 1980s, would be reopened and purchase large amounts of the farmers' produce. Consequently, many farmers increased their production substantially, only to find that the factory suffered infrastructural and managerial problems, and only started buying tomatoes when the season had almost ended.

In 2008, the tomato market was extraordinarily good, but demand outstripped supply, as production had drastically reduced following the previous year's crises. Many farmers in the research area lacked the necessary capital to farm - first because of the aforementioned crises and secondly because they lost most of their rainy season crops due to a combined impact of drought and flood in the rainy season of 2007/08. Burkinabè farmers had also incurred substantial losses during the time the border had been blocked by the Ghanaian government and had therefore switched part of their production to other vegetables and phased out their tomato production in a way that hit the market when Ghanaian farmers had already gone out of production. The demand for tomato increased as the tomato factory, despite some logistical problems, finally started purchasing. Many farmers were content that the factory was now running, but the prices it offered were low, which meant that the farmers only sold those tomatoes to the factory that the market ladies refused to buy.

The low prices the factory offered were the consequence of steep international competition, as it had to compete with producers from Europe, America and Asia that exported cheap tomato products into Ghana. Since 1998, Ghana has seen a major import surge in tomato products. Imports rose from 3,300 tonnes in 1998 to 24,740 tonnes in 2003, an increase of $650 \%$. Consequently, the market share of local tomatoes fell from $92 \%$ to 57\% (FAO 2006: 2). According to FAO (FAOSTAT 2008), imports of tomato products increased further to 96,000 tonnes in 2005. In between 1999 and 2003, major exporters of tomato paste to Ghana came from the EU (54\%, mainly Italy), China (16\%), USA (8\%), Turkey (7\%), and Chile (5\%) (FAO 2006: 2). Exporters are able to offer cheap tomato products because of a high degree of mechanisation and economies of scale, as well as high agricultural and export subsidies. In the EU, for instance, between 2001 and 2008, the production of processing tomatoes was subsidised by $34.50 €$ per metric tonne, which amounted to approximately $50 \%$ of the growers' prices and producers' turnover (Bunte 2007: 6, FAO: 2). Additionally, exports from Italy in 2001, for instance, were supported by EU export refunds of $45 € /$ tonne (about 10\% of wholesale prices) (FAO 2006: 2). China, which has seen an extreme rise in processing tomato production over the last few years, has also introduced subsidies for tomato production since 2007, and tomato paste exports are facilitated by the artificially low exchange rate of the Yuan against the USD (Zhang et al. 
2010: 43, 73). Conversely, agricultural subsidies in Ghana have been abolished since the structural adjustment programmes (SAPs) of the early 1980s, and farmers have found it difficult to compete with low international prices. International competition curtails the national demand for fresh tomatoes, and puts pressure on real prices in Ghana, which have also declined against the prices of agricultural inputs (Amikuzuno 2009: 113). International competition also renders tomato processing in Northern Ghana unprofitable. The tomato paste factory in Pwalugu, which was reopened with considerable government funding in 2007 , operated fully in 2008, the year of the national elections, largely reduced its operations in 2009 and never operated in 2010 . The closure of the factory once again leaves local tomato farmers without access to processing facilities and alternative market channels.

The unfair conditions of international, regional and national tomato (product) trade largely limit the adaptive capacity that tomato production under SGI could have. Similar drawbacks of SGI can be observed in the onion growing areas close to Bawku. Since onions are not as perishable as tomatoes, farmers can avoid gluts by storing their produce. However, marketing cartels as well as regional and global competition lead to low prices and potential losses for local farmers (Blench and Dendo 2007: 4).

\section{Conclusion: ecological change, economic globalisation and the dynamics and limits of local adaptation}

This paper set out to show how small-scale farmers in the Atankwidi and Anayere catchments of the UER of Northern Ghana try to reduce poverty and adapt to changing environmental conditions through the farmer-driven development of SGI. The research area belongs to the poorest region of Ghana, with more than $80 \%$ of the rural population having an income below the official poverty line. Apart from persistent poverty, the area is affected by severe environmental change. Degradation comes partly as a result of the local dynamics of population growth, poverty and unsustainable resource exploitation, which are aggravated by a framework of international and national policies that inhibit the intensification of rain-fed agriculture, but are also caused by the impact of global climate change that has started to affect the local climate. Faced with unreliable environmental and changing economic and political conditions, local small-scale farmers have developed diversified livelihood strategies that range from hunting and gathering, fishing, agro-pastoral production, mixed cropping and (petty) trade to (migrant) wage labour. Adaptation in the realm of agricultural production is derived through the adoption of new rainy season crops, changes in rainy season cultivation patterns and the expansion of SGI.

The will and ability of African smallholders to integrate actively into the market economy has sometimes been disputed, and traditional values and traditional solidarity are blamed or praised for their ability to counteract external policies aimed at the development of rural societies. However, as has been the case in other areas of Ghana, as well as across the African continent, small-scale farmers in the research area have proved their ability to respond to new opportunities, as well as to adopt innovations in the face of major economic and environmental challenges. In doing so, they rely heavily on the same local norms and values that are often blamed for counteracting innovation. Local solidarity and reciprocity help to obtain access to land and labour, and are crucial for the sharing of knowledge and the diffusion of innovations. The advantage of farmer-driven SGI is its local social, cultural and institutional embedding. The sharing of land, labour and knowledge among farmers makes SGI a technology that is comparatively easy to adopt-even by poor farmers. 
Furthermore, SGI has positive adaptive effects for many practicing small-scale farmers, and results in higher food security and standards of living.

Nevertheless, SGI also carries certain risks and limitations as an adaptive strategy, as crop diseases and water shortages affect the yields of tomato production and sometimes endanger the whole harvest. In particular, intensified and expanded SGI can become a threat to other water users and cause environmental problems, as can be seen in South Asia, the Middle East or Northern Africa, where unsustainable groundwater irrigation leads to problems such as regionally lowered groundwater tables, the decreasing quality and availability of domestic or industrial water, saltwater intrusion in coastal aquifers and the drying up of groundwater-related wetlands (Comprehensive Assessment of Water Management in Agriculture 2007: 176 ff). Nevertheless, groundwater irrigation and SGI in particular, especially in areas with low yielding aquifers, where regional overexploitation is unlikely since the drawdown of individual wells becomes excessive, could be an important low-cost cornerstone of poverty reduction and climate change adaptation in Africa, if paralleled by adequate resource mapping and management (MacDonald et al. 2009) .

The largest threat to the local irrigation economy, however, is neither a diminishing resource base nor imperfect agricultural practices. While farmers try to integrate in the larger economy in order to overcome poverty and to adapt to environmental changes, they become subject to market failures that are partially the result of monopolistic local market channels, but are also in their essence caused by unfair and unpredictable patterns of global trade.

This observation is not new, and many development efforts and initiatives for economic growth have been doomed to failure under the prevailing macro-economic conditions of global markets. However, it is the double exposure to global environmental change and economic globalisation, the intensification of trade and the falling of political barriers towards trade (at least in the south) that need to be taken into consideration when local adaptive capacities are discussed. There are already enough convincing arguments that call for the revision of some of the most unfair and devastating economic practices; however, the need to enhance adaptive capacity towards global climate change for poor parts of the population in the south should be added to the discussion.

Acknowledgements The research for this article was conducted in the GLOWA Volta Project, funded by the German Federal Ministry for Education and Research (BMBF), and the Shallow Groundwater Irrigation Project (CP 65), funded by the Challenge Project for Water and Food. The reviews of Nick van de Giessen, Dpt. of Water Resources Management, Technical University of Delft, and Steve Tonah, Dept. of Sociology, University of Ghana, Legon, greatly helped to enhance the quality of the paper.

\section{References}

Adams AM, Cekan J, Sauerborn R (1998) Towards a conceptual framework of household coping: Reflections from Rural West Africa, Africa. Journal of the International African Institute 68:263-283

Adu SV (1972) Eroded Savannah soils of the Navrongo-Bawku area, Northern Ghana. Ghana J Agric Sci 5:3-12 Amegashitsi J (2009) Northern seasonal migrants in Techiman (M.A. thesis). University of Ghana, Accra

Amikuzuno J (2009) Spatial price transmission and market integration in agricultural markets after liberalization in Ghana: Evidence from fresh tomato markets $\mathrm{PhD} \mathrm{Ph} . \mathrm{D}$. Dissertation, University Goettingen, Goettingen

Austin G (2008) Resources, techniques, and strategies south of the sahara: revising the factor endowments perspective on african economic development, 1500-2000. Econ Hist Rev 61:587 
Awo M (2007) Tomatoes in Northern Ghana: Rrisky business or a way out of poverty (M.A. thesis). Institute of Social Science (ISS), The Hague

Barry B, Murali G, Kortatsi B, Forkuor G, Namara R, van den Berg J, Laube W (2010) Understanding Shallow Groundwater Irrigation in the White Volta Basin. Current extent and future sustainability. IWMI Research Report. IMWI, Colombo

Bates RH (1981) Markets and states in tropical Africa. University of California Press, Berkley

Berry S (1993) No condition is permanent: the social dynamics of agrarian change in Sub-Saharan Africa. University of Wisconsin Press, Madison

Blench R (2006) Agriculture and the environment in northeastern Ghana: a comparison of high and medium population density areas. Overseas Development Institute, London

Blench R, Dendo M (2007) Agricultural production and the potential for commodity chain expansion in the three northern regions of Ghana in 2006. http://www.rogerblench.info/Development/Ghana/FAO/Blench \%20Working\%20Paper\%20Ghana\%202006\%20revised.pdf. Accessed 21 November 2010

Boko M, Niang I, Nyong A et al (2007) Africa. In: Parry ML, Canziani OF, Palutikof JP et al (eds) Climate change 2007: impacts, adaptation and vulnerability. Contribution to the fourth assessment report of the intergovernmental panel on Climate change, Cambridge University Press, Cambridge, pp 433-467

Boserup E (1965) The Conditions of agricultural growth. Aldne, Chicago

Braimoh AK, Vlek PLG (2005) Land cover change trajectories in Northern Ghana. Environ Manag 36:356-373

Bryceson DF (2002) The scramble in Africa: reorienting rural livelihoods. World Development 30:725

Bunte F (2007) Peeling tomato paste subsidies. Adding Value to the Agro-Food Supply Chain in the Future Euromediterranean Space, 1. Mediterranean Conference of Agro-Food Social Scientists, Barcelona, Spain

Carter MR (1997) Environment, technology, and the social articulation of risk in West African Agriculture. Econ Dev Cult Chang 45:557-590

Carter RC, Howsam P (1994) Sustainable use of groundwater for small-scale irrigation: with special reference to sub-Saharan Africa. Land Use Policy 11(4):275

Chalfin B (2003) The North Goes Global: Export Markets and Indigenous Commodities. In: Kröger F, Meier B (eds) Ghana's North. Research on Culture, Religion, and Politics of Societies in Transition. Peter Lang, Frankfurt a. M., pp 21-43

Clark G (1997) Managing transitions and continuities in Ghanaian trading contexts. Afr Econ Hist 32:65-88

Codjoe SNA (2004) Population and land use/cover dynamics in the Volta river basin of Ghana 1960-2010 Doctoral Thesis, University of Bonn

Collier P, Conway G, Venables T (2008) Climate change and Africa. Oxford Rev Econ Pol 24:337-353

Comprehensive Assessment of Water Management in Agriculture (2007) Water for Food, Water for Life: A Comprehensive Assessment of Water Management in Agriculture. London, Earthscan and Colombo, International Water Management Institute

Conley T, Udry C (2001) Social learning through networks: the adoption of new agricultural technologies in Ghana. Am J Agric Econ 83:668-673

Derbile E, Laube W, Schraven B (forthcoming) Between tradition and innovation: livelihood dynamics in the Upper Volta Basin of Northern Ghana. ZEF Working Papers, Center for Development Research, University of Bonn

Dietz AJ, Millar D, Dittoh S, Obeng F, Ofori-Sarpong E (2004) Climate and livelihood change in North East Ghana. In: Dietz AJ, Ruben R, Verhagen A (eds) The impact of climate change on drylands with a focus on West Africa. Kluwer Academic Publishers, Dordrecht, pp 149-172

Eakin H (2005) Institutional change, climate risk, and rural vulnerability: cases from Central Mexico. World Development 33:1923-1938

Ellis F (1998) Household strategies and rural livelihood diversification. J Dev Stud 35(1):1-38

Elwert G (1983) Bauern und Staat in Westafrika: Die Verflechtung sozioökonomischer Sektoren am Beispiel Benin. Campus, Frankfurt a. M.

Fairhead J, Leach M (1996) Misreading the African landscape: society and ecology in a forest savannah mosaic. Cambridge University Press, Cambridge

FAO (2006) FAO Briefs on Import Surges. Ghana:rice, poultry and tomato paste. FAO, Rome

FAOSTAT (2008) Ghana: Import Quantity Pate of Tomatoes. FAO. http://faostat.fao.org/site/535/Desktop Default.aspx?PageID=535. Accessed 15 April 2008

Fortes M (1936) Culture contact as a dynamic process. Africa 9:24-55

Giordano M (2006) Agricultural groundwater use and rural livelihoods in sub-Saharan Africa: a first-cut assessment. Hydrogeol J 14:310-318

GSS (1989) 1984 population and housing census of Ghana special report on localities by local authorities: Upper East Region. Ghana Statistical Services, Accra 
GSS (2000) Poverty trends in Ghana in the 1990s. Ghana Statistical Services, Accra

GSS (2002a) 2000 population and housing census - special reports on 20 largest localities. Ghana Statistical Service, Accra

GSS (2002b) 2000 population and housing census: summary report of final results. Ghana Statistical Services, Accra

Gyasi KO (2005) Determinants of Success of Collective Action on Local Commons: An Empirical Analysis of Community-Based Irrigation Management in Northern Ghana. Peter Lang, Frankfurt a. M.

Hulme M (2001) Climatic perspectives on Sahelian desiccation: 1973-1998. Global Environ Change 11 (1):19-29

Hussain I, Ahanjra M (2004) Irrigation and poverty alleviation: review of the empirical evidence. Irrig Drain 53:1-15

Hyden G (1980) Beyond Ujamaa in Tanzania: underdevelopment and an uncaptured peasantry. Heinemann, London

Jung G, Kunstmann H (2007) High-resolution regional climate modelling for the Volta Basin of West Africa. J Geophys Res 112:17

Konings P (1986) The state and rural class formation in Ghana: a comparative analysis. Keegan Paul, London

Kpongor DS (2007) Spatially explicit modeling of sorghum (Sorghum bicolour (L.) Moench) production on complex terrain of a semi-arid region in Ghana using APSIM. Doctoral thesis, University of Bonn

Kranjac-Brisavljevic G, Bayorbor TB, Obeng F (1999) Rethinking natural resource degradation in semi-arid Sub-Saharan Africa: the case of semi-arid Ghana. Overseas Development Institute/University of Development Studies, London

Kumedzro RU (1970) The population geography of the Kassena-Nankani District, Upper Region: from 1900 to the present (BA Thesis). University of Ghana

Lambert MC (2002) Longing for Exile. Migration and the Making of a Transnational Community in Senegal, West Africa. Heinemann, Portsmouth

Laube W (2007) Changing resource regimes in Northern Ghana: actors, structures and institutions. LIT, Berlin

Laube W, Le QB (2007) Development options for the sustainable use of land and shallow groundwater in Atankiri and anayere catchments: report of the farmer workshop, Narvongo, Ghana on 20-22 July, 2007. Centre for Development Research, Bonn

Laube W, Awo M, Schraven B (2008) Erratic Rains and erratic markets: environmental change, economic globalisation and the expansion of shallow groundwater irrigation in West Africa. ZEF Working Papers Nr. 30, Center for Development Research, University of Bonn

Laux P, Kunstmann H, Bárdossy A (2008) Predicting the regional onset of the rainy season in West Africa. Int J Climatol 28:329-342

Lay J, Narloch U, Mahmoud TO (2009) Shocks, Structural Change, and the Patterns of Income Diversification in Burkina Faso. Afr Dev Rev 21(1):36-58

Lentz C (1998) Die Konstruktion von Ethnizität: eine politische Geschichte Nord-West Ghanas 1870-1990. Rüdiger Köppe, Köln

Levy P, Lemeshow S (1999) Sampling of populations: methods and applications. Wiley, New York

MacDonald AM, Calow RC, MacDonald DMJ, Darling GW, Dochartaigh B (2009) What impact will climate change have on rural groundwater supplies in Africa? Hydrol Sci J 54(4):690-703

Nabila JS (1987) The migration of the Fra-Fra in Northern Ghana: a case study of cyclical labour migration in West Africa. Doctoral thesis, Michigan State University

News in Ghana (2004) Livelihood of tomato farmers in UER under threat. News in Ghana. Available at http://www.modernghana.com/news/62773/1/livelihood-of-tomato-farmers-in-uer-under-threat.html. Accessed 20 September 2008

Niasse M (2005) Climate-induced water conflict risks in West Africa: recognizing and coping with increasing climate impacts on shared watercourses, in Human Security and Climate Change. Holmen Fjord Hotel, Asker, Oslo, pp 1-15

Nielsen JØ, Reenberg A (2009) Temporality and the problem with singling out climate as a current driver of change in a small West African village. J Arid Environ 74(4):464-474

O'Brien K, Leichenko RM (2000) Double exposure: assessing the impacts of climate change within the context of economic globalisation. Glob Environ Chang 10:221-232

O'Brien K, Leichenko RM, Kelkar U et al (2004) Mapping vulnerability to multiple stressors: climate change and globalisation in India. Glob Environ Chang 14:303-313

Olivier de Sardan JP (1988) Peasant logics and development project logics. Sociol Rural 28:216-226

Padmanabhan MA (2007) The making and unmaking of gendered crops in Northern Ghana. Singap J Trop Geogr 28(1):57-70. doi:10.1111/j.1467-9493.2006.00276.x

Paeth H (2004) SST versus climate change signals in West African rainfall: 20th-century variations and future projections. Clim Chang 65(1/2):179-208 
Reid RS, Kruska RL, Muthui N, Taye A, Wotton S, Wilson CJ, Mulatu W (2000) Land-use and land-cover dynamics in response to changes in climatic, biological and socio-political forces: the case of southwestern Ethiopia. Landsc Ecol 15(4):339-355. doi:10.1023/a:1008177712995

Roncoli C, Ingram K, Kirshen P (2002) Reading the rains: local knowledge and rainfall forecasting in Burkina Faso. Soc Nat Resour Int J 15(5):409-427

Rostow W (1987) The stages of economic growth: a non-communist manifesto, 2nd edn. Cambridge University Press, Cambridge

Sandbrooke R (1985) The politics of Africa's economic stagnation. Cambridge University Press, Cambridge

Schindler J (2009) A multi-agent system for simulating land-use and land-cover change in the Atankwidi catchment of Upper East Ghana. Doctoral thesis, University of Bonn

Schraven B (2010) Irrigate or migrate? Local livelihood adaptation in Northern Ghana in response to ecological changes and economic challenges. Doctoral thesis, University of Bonn

Scoones I (2009) Livelihoods perspectives and rural development. J Peasant Stud 36:171-206

Scott JC (1976) The moral economy of the peasant. Yale University Press, New Heaven

Sinnadurai S, Abu J (1977) Onion farming in Ghana. Econ Bot 31(3):312-314. doi:10.1007/bf02866882

Songsore J (1996) Population growth and ecological degradation in Northern Ghana: myths and realities. Res Rev (NS) 12:51-66

Tiffen M, Mortimore M, Gichuki F (1994) More people, less erosion - environmental recovery in Kenya. Wiley, Chichester

Tonah S (1993) The development of agropastoral households in Northern Ghana: policy analysis, project appraisal and future perspectives. Verlag für Entwicklungspolitik, Saarbrücken

Tosh J (1980) The cash-crop revolution in tropical africa: an agricultural reappraisal. Afr Aff 79(314):79-94

Tripp R (1992) Dietary consequences of changes in trade and agriculture for the Nankane of Northern Ghana. Ecol Food Nutr 27:249-258

Van de Giesen N, Liebe J, Jung G (2010) Adapting to climate change in the Volta Basin, West Africa. Curr Sci 98:1033-1037

Whitehead A (2006) Persistent Poverty in North East Ghana. J Dev Stud 42(2):278-300

World Bank (2007) World Bank Assistance to agriculture in Sub-Saharan Africa: An IEG Review, Independent Evaluation Group. World Bank, Washington, p 144

Zhang X, Qui H, Huang Z (2010) Appel and Tomato Chains in China and the EU. LEI-Report, vol 2010019. LEI, Wageningen 